\title{
Modeling the Impacts of Urbanization on Regional Climate Change: A Case Study in the Beijing-Tianjin-Tangshan Metropolitan Area
}

\author{
Jinyan Zhan, ${ }^{1}$ Juan Huang, ${ }^{1}$ Tao Zhao, ${ }^{2}$ Xiaoli Geng, ${ }^{3}$ and Yihui Xiong ${ }^{4}$ \\ ${ }^{1}$ State Key Laboratory of Water Environment Simulation, School of Environment, Beijing Normal University, Beijing 100875, China \\ ${ }^{2}$ Bureau of Science and Technology for Development, CAS, Beijing 100864, China \\ ${ }^{3}$ School of Resources and Environmental Science, Hubei University, Hubei 430062, China \\ ${ }^{4}$ School of Information Engineering, China University of Geosciences (Wuhan), Hubei 430074, China
}

Correspondence should be addressed to Jinyan Zhan; zhanjy@bnu.edu.cn

Received 18 July 2013; Revised 23 September 2013; Accepted 7 October 2013

Academic Editor: Xiangzheng Deng

Copyright (C) 2013 Jinyan Zhan et al. This is an open access article distributed under the Creative Commons Attribution License, which permits unrestricted use, distribution, and reproduction in any medium, provided the original work is properly cited.

\begin{abstract}
China has experienced rapid urbanization since 1978, and the dramatic change in land cover is expected to have significant impacts on the climate change. Some models have been used to simulate the relationship between land use and land cover change and climate change; however, there is still no sufficient evidence for the impacts of urbanization on the regional climate. This study aims to identify the impact of urban land use change on regional temperature and precipitation in summer in the Beijing-TianjinTangshan Metropolitan area during 2030-2040 based on the analysis of the simulation results of WRF model. Firstly, we analyzed the land use change and climate change during 1995-2005 in the study area. The impacts of future urbanization on regional climate change were then simulated. The results indicate that urbanization in this area has affected the regional climate and has the potential to increase temperature and precipitation in the summer of 2030-2040. These research results can offer decision-making support information related to future planning strategies in urban environments in consideration of regional climate change.
\end{abstract}

\section{Introduction}

More than $50 \%$ of the world's people live in cities, and the urban population is growing at a much faster rate than the Earth's population as a whole and by larger annual increments than ever before [1]. It is expected that $61 \%$ of the world's population will reside in urban settlements in 2030 [2], and China's current plan is to make the proportion of urban population reach $67 \%$ in 2030 , shifting 280 million people to cities within two decades [3]. Some studies have shown that the population size of China will reach the peak around 20302040 and thereafter decline gradually, shifting from the low growth phase to a negative growth phase. The climate system involves the land surface, atmosphere, oceans and other water bodies, the cryosphere and the biosphere, and urbanization which is one of the most important human activities that influence the climate system [4]. Urban climates are warmer and more polluted than their rural counterparts [5]. These differences are partly due to the urban expansion, which usually removes and replaces crops and natural vegetation with nonevaporating and nontranspiring surfaces such as metal, asphalt and concrete [6]. There is generally low land surface albedo, vegetative cover, and moisture availability in urban areas. These factors, along with the presence of high levels of anthropogenic heating, are associated with the phenomenon known as the urban heat island (UHI), which describes the difference in ambient air temperature between an urban area and its surrounding rural area [5]. UHI often occurs when a large fraction of the natural land cover in an area is replaced by the built surfaces that absorb the incoming solar radiation during the day and then reradiate it at night $[7,8]$. UHI has been the most intensively studied climatic 
feature of cities and has been quantified by calculating air or surface temperature differences between urban and nearby rural areas [9-12].

A number of studies have indicated that there is some relationship between urbanization and climate change. For example, Bornstein found that there is less intense and less frequent urban surface temperature inversion in New York City than in the surrounding nonurban regions [13]. The research of Kalnay and Cai suggested that half of the observed decrease in the diurnal temperature was due to urban expansion and other land use changes [14]. Sertel et al. indicated that urbanization increased the average temperature in Turkey according to the results of simulation with the Weather Research and Forecasting (WRF) regional climate model [15]. In fact, the WRF model has been widely used in previous researches that focus on the impacts of future urbanization on climate change $[16,17]$. What is more, urbanization can also influence the regional precipitation [18]. For instance, Huff and Vogel and Vogel and Huff found that the urban surface was the main factor affecting the spatial and temporal pattern and the intensity of short-term rainfall in St. Louis, MO, USA $[19,20]$. Shepherd et al. showed that the rainfall was modified by major urban areas according to the observation data from space-borne rain radar on the TRMMsatellite [21]. Many modeling studies have also indicated that the urbanization increased the surface convergence on the leeward side of the urban region and consequently led to increased precipitation [22-24]. For example, Rozoff et al. and Heever et al. showed that urban-enhanced aerosols could exert significant influence on the dynamics, microphysics, and precipitation once convection was initiated, and the impacts of urban aerosols on the downwind storms decrease with the background aerosol concentration $[24,25]$.

Previous researches have analyzed the effects of the urban land surface change at the microscale; however, it is also necessary to study how both the past and future urbanizations might affect the weather and climate. In particular, it is very necessary to analyze how these effects can extend beyond the city, affecting the climate at the regional scale [26]. It is urgent to develop a metric to quantify how urbanization affects the regional climate since the neglection of these effects will lead to inaccurate analysis results of climate change [4]. Besides, the metropolitan cities in China have shown the "spreading" and "aggressive" expansion accompanied by regional urban development and megalopolis formation since the reform and opening up [27-29], resulting in increasing effects on climate change [30-33]. Beijing-Tianjin-Tangshan Metropolitan area is the economic center of northern China, and it plays a strategically important role in the political and economic development of China as a whole [34]. Therefore, the primary objectives of this study are (1) to analyze the relationship between urbanization and climate in the Beijing-TianjinTangshan Metropolitan area during 1995-2005 and (2) to identify the impact of urbanization on temperature and precipitation in summer based on the difference between two scenario simulations during 2030-2040. Section 2 introduces the study area and the simulation process, which also includes the data resource. The results and discussions are shown in Section 3 and Section 4 concludes.

\section{Data and Methodology}

2.1. Study Area. The Beijing-Tianjin-Tangshan Metropolitan area is located in northeast North China Plain between $38^{\circ} 25^{\prime}-41^{\circ} 5^{\prime} \mathrm{N}$ and $115^{\circ} 25^{\prime}-119^{\circ} 25^{\prime} \mathrm{E}$. It covers Beijing Municipality, Tianjin Municipality and the cities of Tangshan, Langfang, and Qinhuangdao (TLQ) of Hebei Province, with a total area of $55,000 \mathrm{~km}^{2}$ and a resident population of $29,368,600$. This region is mainly mountain and plain, and the hilly area is $1.98 \mathrm{~km}^{2}$. The area belongs to the continental monsoon climate. The average annual temperature is between $10^{\circ} \mathrm{C}$ and $12^{\circ} \mathrm{C}$, with the mean temperature of $-1.9^{\circ} \mathrm{C}$ in January and $26.4^{\circ} \mathrm{C}$ in July. The average annual precipitation is between 75 and $500 \mathrm{~mm}$ with an uneven time distribution, which mainly occurs during summer with $72 \%$ of the total annual rainfall.

Owing to the superior natural condition and critical strategic location of the Beijing-Tianjin-Tangshan Metropoli$\tan$ area, it is defined as the political, cultural, and economic center of China. The National Eleventh Five-Year Plan concluded the development of this region. The BeijingTianjin-Tangshan Metropolitan area developed quickly with high land use intensity, especially in large-scale science and technology parks, economic zones, industrial parks, and other new development zones. Thus, the conflict between rapid city growth and water and soil resources has become increasingly pronounced [35], and currently it is one of the most stressed areas for such problems in China.

2.2. Simulation Scheme. The Weather Research and Forecasting (WRF) model based on the Eulerian mass solver was used in this study to investigate the temperature and precipitation change driven by the future urban expansion in the study area. This mesoscale model is a state-of-the-art atmospheric simulation system based on the Fifth-Generation Penn State/NCAR Mesoscale Model (MM5) [34], and it has been widely used in global climate and regional climate research, and it has achieved good results [36-40].

This study simulated the climate change in the BeijingTianjin-Tangshan Metropolitan area during 2030-2040 based on two tests with the WRF model. Two simulation tests were conducted for the summer (June-August) during 2030-2040 (Table 1) with the WRF model under the same condition except the underlying surface in order to indicate the impact of urbanization on temperature and precipitation. First, the underlying surface data of 1992-1993 in the WRF model was replaced since it cannot exactly reflect the land surface condition after 2000. The land cover data in 2010 were used as the underlying surface data for the control test, and the land cover data in 2030 predicted on the basis of the trend of social-economic simulation were used for the sensitivity test. Then, the simulation results of the control test and sensitivity test were compared, and the effects of urbanization on the summer temperature and precipitation were finally examined. The effects of the future urban expansion on the climate can be explained with $E_{i}$. Consider the following:

$$
E_{i}=R_{i}-r_{i}
$$


TABLE 1: Schemes of the simulation test.

\begin{tabular}{lcc}
\hline Test & Test time & Land cover data used in WRF \\
\hline $\begin{array}{l}\text { Control } \\
\text { test }\end{array}$ & 2030.01.01-2040.12.31 & Land cover data of 2010 \\
$\begin{array}{l}\text { Sensitivity } \\
\text { test }\end{array}$ & $2030.01 .01-2040.12 .31$ & Land cover data of 2030 \\
\hline
\end{tabular}

TABLE 2: Configuration of the physical parameterization schemes in WRF.

\begin{tabular}{lc}
\hline Physical processes & Scheme option \\
\hline Microphysics scheme & Lin et al. [16] \\
Cumulus scheme & Grell-Devenyi ensemble \\
Land surface process & Noah land surface model \\
Planetary boundary layer process & YSU scheme \\
Short-wave radiation & CAM scheme \\
Long-wave radiation & CAM scheme \\
\hline
\end{tabular}

where $i$ refers to the precipitation and temperature, $E_{i}$ is the effect of the future urbanization on the climate, $R_{i}$ is the result of the simulation with the predicted underlying surface, and $r_{i}$ is the result of the simulation with the baseline underlying surface.

The parameterization schemes in this study are listed in Table 2. The Grell-Devenyi ensemble scheme was adopted in the cumulus parameterization scheme, with YSU being the boundary layer process scheme, and the CAM scheme being both long-wave radiation and short-wave radiation schemes, while the land surface process scheme was the Noah land surface model. The boundary buffer was set to be 4 layers of grid points, and the relaxation scheme was adopted in the boundary conditions. The time interval of the model integration was set to be 5 minutes and that of the radiation process and cumulus convection was 30 minutes and 5 minutes, respectively. There were 27 layers in the vertical direction, and the atmospheric pressure at the top layer was $50 \mathrm{hPa}$.

The lateral boundary forcing data was from the National Centers for Environmental Predictions (NCEP) operational Global Final (FNL) Analyses (NCEP/FNL) and was updated every 6 hours. The dataset was established on the basis of the assimilation of almost all kinds of observational data (e.g., remote sensing data and ground-based observation data) with a spatial resolution of $1^{\circ} \times 1^{\circ}$ gird and a vertical height of 27 layers, and it has been updated to the present time since July, 1999. Compared with the dataset of NCEP I, NCEP II, and EAR40, the NCEP/FNL not only has the higher accuracy and spatial resolution but also involves more kinds of environmental variables. The data of future force filed were from the fifth phase of the Coupled Model Intercomparison Project (CMIP5) which produces a state-ofthe-art multimodel dataset. The model output analyzed by researches forms the basis for the Fifth Assessment Report of the Intergovernmental Panel on Climate Change [41], and two time scales of projections of future climate change are provided. The first one is the near term (out to about 2035), and the other one is the long term (out to 2100 and beyond).
Model output of the RCP 6.0 such as air temperature, specific humidity, sea level pressure, eastward wind, northward wind, and geopotential height from 2010 to 2040 was used as the atmospheric forcing dataset of the WRF model.

Urban land use data, which were extracted from Landsat TM images in 1995 and Landsat ETM images from the ChinaBrazil Earth Resources satellite (CBERS) in 2005 [42, 43], was acquired from the data center of the Chinese Academy of Sciences. The land use change during 1995 to 2005 has been described in Table 3 . The predicted land use and land cover data in 2030 were derived from the database of Representative Concentration Pathway (RCP 6.0). The new urban area pixels during 2010-2030 derived from RCP 6.0 were overlaid to the map of baseline underlying surface; then the underlying surface data in 2030 was transformed to grid data of $30 \mathrm{~km} *$ $30 \mathrm{~km}$ of USGS data by resampling.

\section{Results and Discussion}

3.1. Spatiotemporal Pattern of Urban Expansion since 1995. The urban expansion is one of the key characteristics of land use change in the Beijing-Tianjin-Tangshan Metropolitan area from 1995 to 2005, the spatiotemporal pattern of which was analyzed according to the remote sensing data (Table 3 ). During 1995 and 2005, the total area of cultivated land and forests decreased by $0.98 \%$ and $2.15 \%$, respectively, while the urban land area increased by $3.34 \%$, with an average annual rate of $0.33 \%$. Urban expansion is the main driving factor of the shrinkage of cultivated land and forests. The center of urban expansion has shifted from Beijing megacity to the periphery cities such as Tianjin and Tangshan due to the regional development strategies and populationresource-environment pressures [34]. The socioeconomic development and geographical factors, such as the population growth, policy, and economic development, all affect the urban expansion and subsequent landscape changes.

\subsection{Spatiotemporal Change of the Temperature and Pre-} cipitation in the Beijing-Tianjin-Tangshan Metropolitan Area during 1995-2005. There was slight temperature change in the Beijing-Tianjin-Tangshan Metropolitan area from 1995 to 2005 (Figure 1). Overall, the temperature showed an increasing trend in most parts of the study area, especially around metropolitan Beijing and in the costal metropolitan area of Tianjin and Tangshan, with an average increasing rate of $0.023^{\circ} \mathrm{C} /$ year. However, the temperature has decreased to some degree in the northeast and northwest part of the study area. The regions that converted from other land use types into cities have shown relatively higher temperature rise, indicating that the urbanization has some influence on temperature in the Beijing-Tianjin-Tangshan Metropolitan area. At the same time, the precipitation showed a rising trend in metropolitan Tangshan and northeast parts of Beijing Metropolitan, while it showed a downward trend in the west and south part of Beijing. According to the results mentioned above, it can be concluded that the process of urbanization in this region has affected the regional temperature 
TABle 3: Land use changes in Beijing-Tianjin-Tangshan Metropolitan area, 1995-2005.

\begin{tabular}{lcccccc}
\hline Year/period & Cultivated land (\%) & Forestry area (\%) & Grassland (\%) & Water area (\%) & Built-up area (\%) & Unused land (\%) \\
\hline 1995 & $48.48 \%$ & $24.59 \%$ & $6.32 \%$ & $5.54 \%$ & $14.14 \%$ & $0.92 \%$ \\
2005 & $47.50 \%$ & $22.45 \%$ & $6.74 \%$ & $5.08 \%$ & $17.48 \%$ & $0.76 \%$ \\
Change 2005-1996* & $-0.10 \%$ & $-0.21 \%$ & $0.04 \%$ & $-0.05 \%$ & $0.33 \%$ & $-0.02 \%$ \\
\hline
\end{tabular}

Note: * represents the change rate calculated with the following equation: $\left(A_{i}^{2005}-A_{i}^{1995}\right) /(10)$, where $A_{i}^{2005}$ means the area proportion of land use type $i$ in 2005 and $A_{i}^{1995}$ means the area proportion of land use type $i$ in 1995.

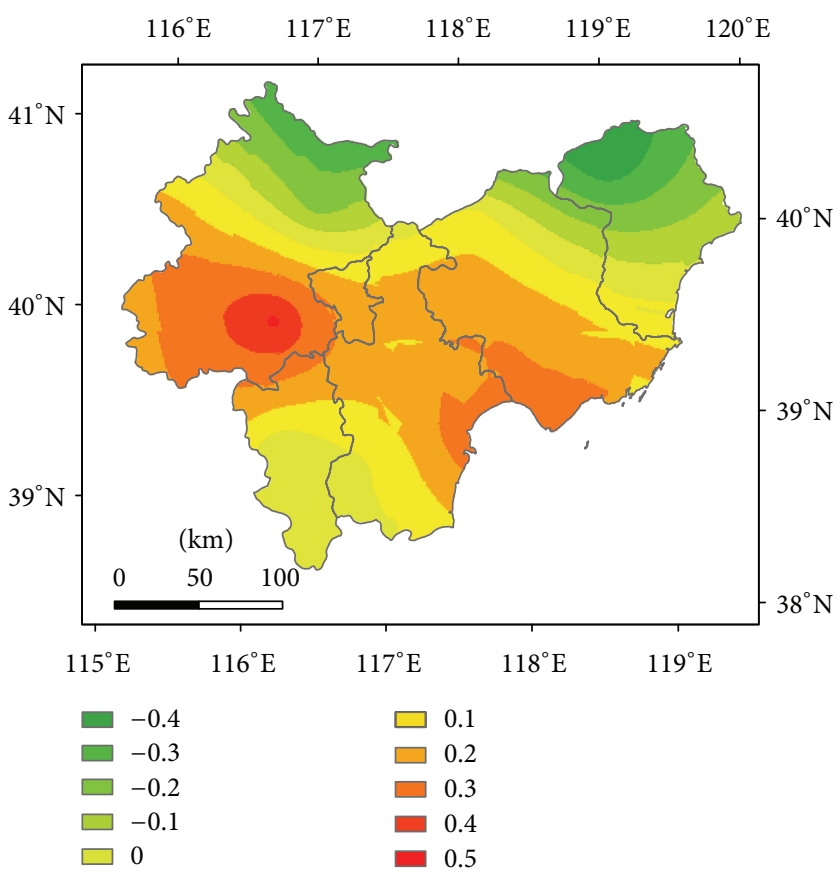

(a)

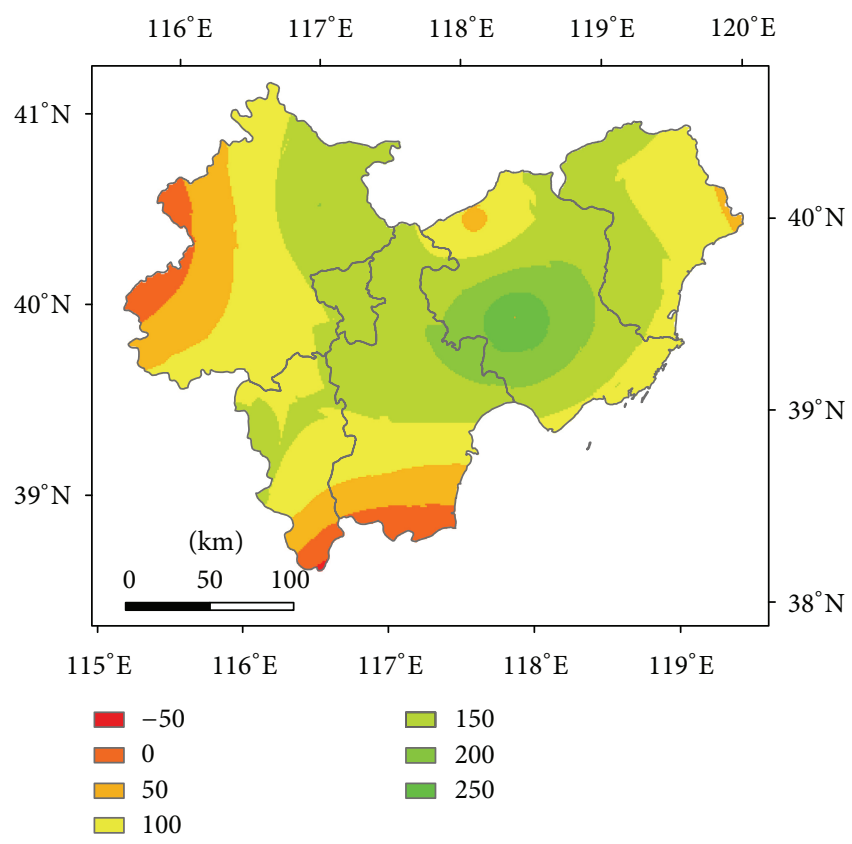

(b)

FIGURE 1: Simulated changes of temperature (a) and precipitation (b) in Beijing-Tianjin-Tangshan Metropolitan area during $1995-2005$.

and precipitation to a certain extent in the Beijing-TianjinTangshan Metropolitan area.

3.3. Urban Area Change from 2010 to 2030. There will be obvious conversion from other land use types to urban area in Beijing-Tianjin-Tangshan Metropolitan area during 20102030 (Figure 2). The urban area in the study area would continue to increase during 2010-2030, and the newly increased urban land will mainly be concentrated in the regions around the downtown of Beijing and Tianjin City. The land use conversion mainly results from the joint effects of both the internal factors and external factors such as the terrain, traffic, and economic factors, behaviors of the government, and cultural tradition [44]. The land cover data in 2010 and 2030 were put into the WRF model and two separate numerical tests were carried out, the simulation results of which were compared, and thereafter the urbanization impacts of urban expansion on the climate were examined.

3.4. Results of the Numerical Simulation. Figure 3 depicted the simulated impact of future urban expansion on the average annual temperature in the study area during 2030-2040.
There will be significant warming effects in the summer, mainly occurring in the downtown and eastern part of Beijing Metropolitan. The transformation of vegetated land to urban land results in significant differences of near-surface temperature. As a result, the temperature would increase obviously in the regions with urban expansion, mainly owning to the urban heat island effect, which is consistent with the results of previous researches $[16,45,46]$.

The surface temperature is determined with the surface energy balance equation. Consider the following:

$$
-\rho L_{v}\left(\overline{w^{\prime}} \overline{q^{\prime}}\right)_{\mathrm{sfc}}+R_{n}-S-\rho c_{p} C_{h} u\left(T_{\mathrm{sfc}}-T\right)=0,
$$

where the first item refers to the latent heat flux, the second item refers to the net radiation flux, the third item refers to the soil heat flux, and the forth item refers to the sensible heat flux.

Part of the net radiation flux is absorbed by the Earth's surface, which further influences the latent heat flux and sensible heat flux, with the rest being transformed into the soil 


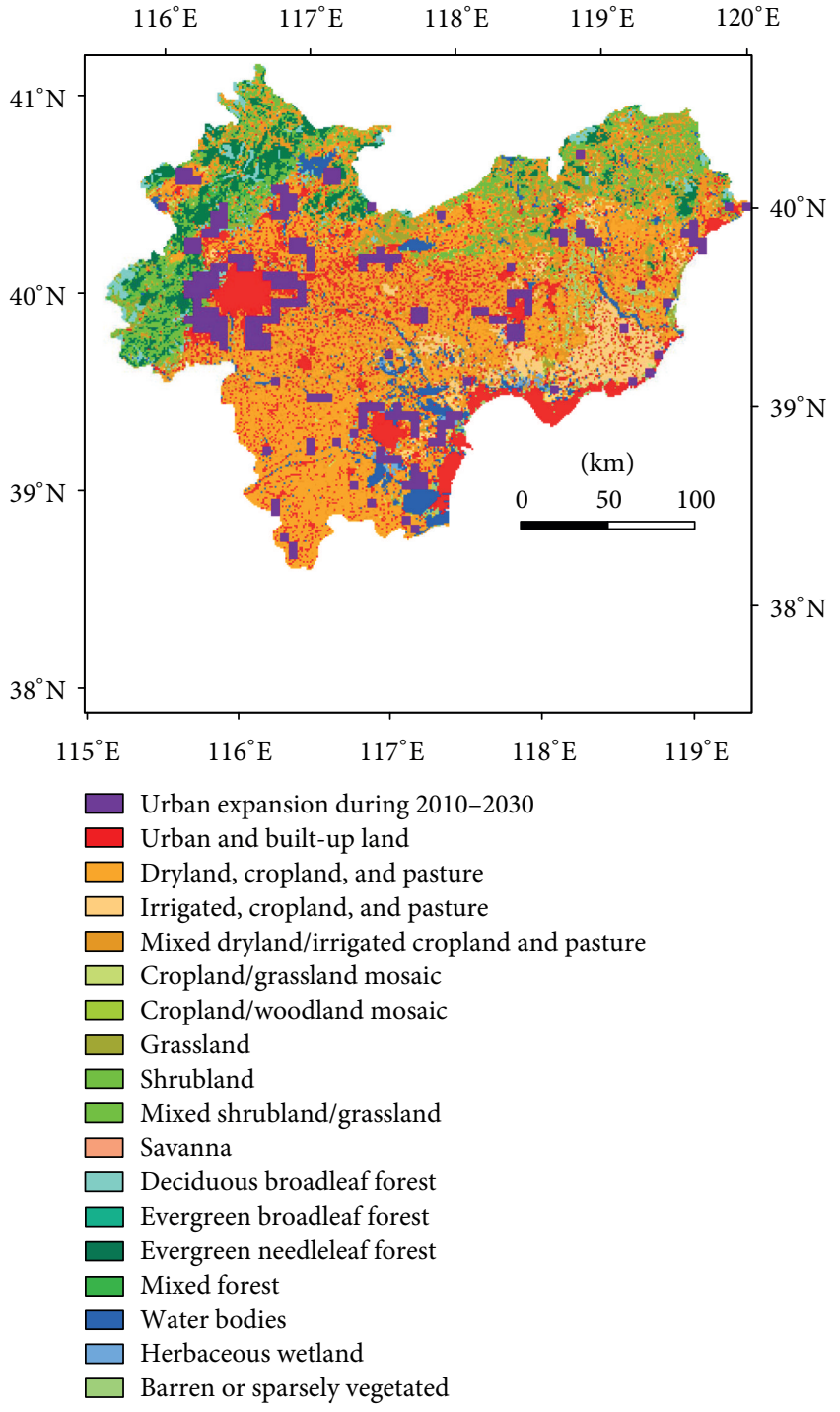

Figure 2: Conversion from other land use types to urban area in Beijing-Tianjin-Tangshan Metropolitan area during 2010 to 2030.

and soil heat flux. The heat transfer in soil complies with the thermal diffusion equation. Consider the following:

$$
C(\Theta) \frac{\partial \Theta}{\partial t}=\frac{\partial}{\partial z}\left(K_{t}(\Theta) \frac{\partial T}{\partial t}\right),
$$

where $T$ is the soil layer temperature, $\Theta$ refers to the soil water content, $C$ means the specific heat of soil layer, $K_{t}$ is the thermal conduction system.

There will be many more populations in the new cities, which will need and consume a lot of heat/power due to their activities (transportation, air conditioning, and industries), thus exerting significant impacts on the balance of surface energy. It has been reported that the surface temperature is determined by the radiation flux, sensible heat flux, latent heat flux, specific heat of soil layer, and thermal conduction system, while the surface temperature also affects the sensible heat flux and latent heat flux $[47,48]$. In the urbanized area,

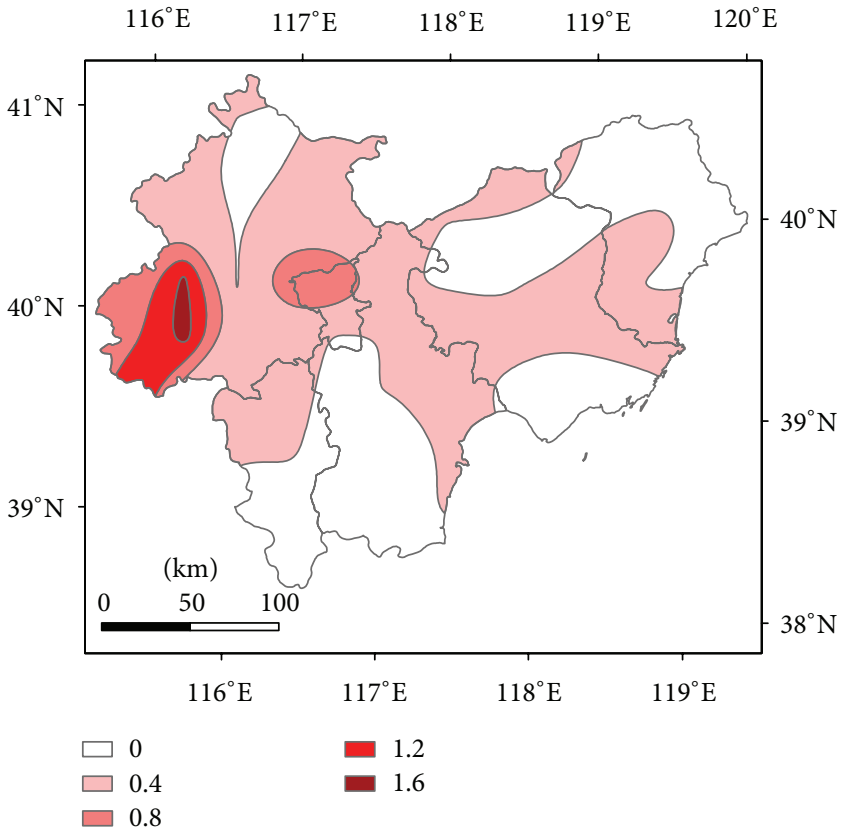

FIGURE 3: Projected summer temperature difference of monthly average temperature between control test and sensitivity test in Beijing-Tianjin-Tangshan Metropolitan area, 2030-2040.

the surface temperature, which magnifies the sensible heat flux and the soil heat flux, will rise due to the increase of the net surface short-wave radiation and decrease of the latent heat flux. All these changes along with the increase of humaninduced heat emission will lead to the temperature rise [49].

The urban expansion has significant impacts on the precipitation in the summer during 2030-2040 in the study area (see Figure 4). In general, there is obvious heterogeneity of the local precipitation change, and there will be some precipitation increase in the urban areas, which may be due to the extended urban boundary and increased secondary outflow activity. Shepherd also showed that the expansion of future urban land cover might result in a more expensive area of rainfall [50]. Urbanization would increase the emission of atmospheric pollutants, cause the heat island effect, and lead to the land use change. The volatile air layer can lead to the thermal convection easily due to the urban heat island effect, which can increase thermal convection and convective precipitation. Moreover, buildings of different heights can not only cause mechanical turbulence but also hinder the moving slow precipitation system, thus leading to the increase of precipitation. At the same time, there are intensive human activities in the urban regions, which lead to the emission of a large amount of greenhouse gases, aerosol, and other particulate matters. On the one hand, these materials increase the condensation nucleus for precipitation; on the other hand, these materials intensify the urban heat island effect in the urban regions. Under the condition of sufficient moisture, there will be more precipitation due to the increased condensation nucleus above the municipal areas and relatively high underlying surface temperature, which may account for 


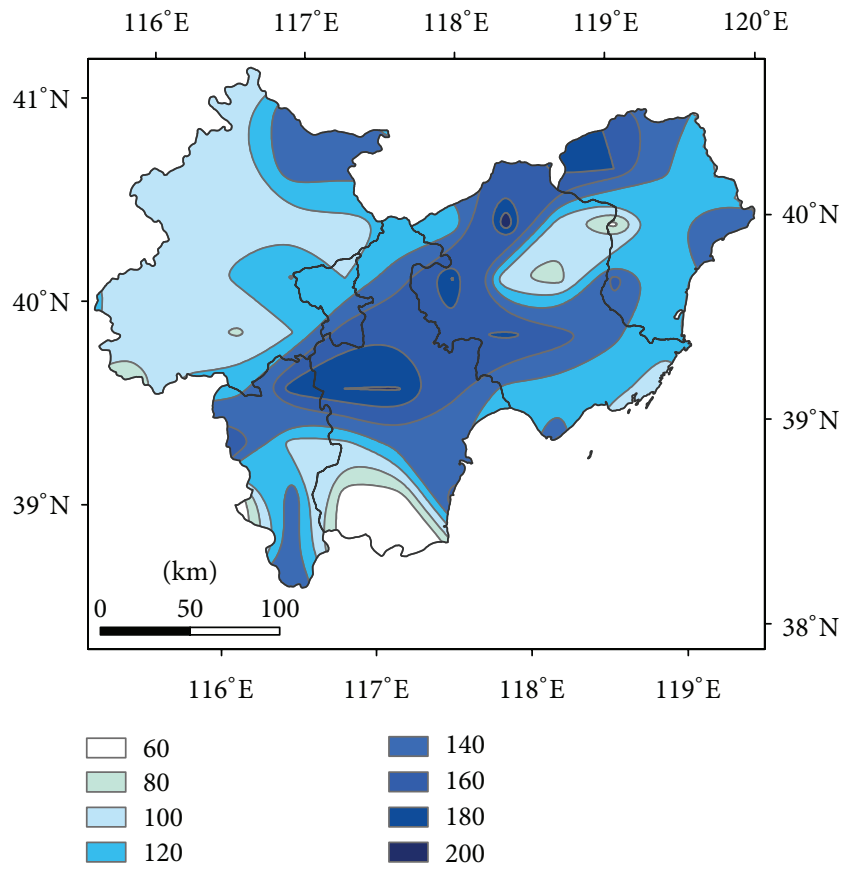

Figure 4: Projected summer precipitation difference of monthly average precipitation between control test and sensitivity test in Beijing-Tianjin-Tangshan Metropolitan area, 2030-2040.

the increase of precipitation in this region in the summer. In summary, the hydroclimate will be directly and indirectly affected by the urban land cover change [51] and the urban expansion will exert more influence on the local climate as the urban development continues.

\section{Conclusions}

The urban climate change results from the interaction between human activities and local climate change in essence. The change of underlying surface properties, human-induced heat emission, and so forth will lead to the difference between the urban and rural temperature, which will further change the local climate forcing field and consequently lead to the redistribution of climate factors such as the wind, cloud, and precipitation. This study investigated the contribution of urban land use change to the change of temperature and precipitation in Beijing-Tianjin-Tangshan Metropolitan area during 2030-2040 with the WRF model based on the latest actual urban land cover data from 1995 to 2005.

The impact of urbanization on regional climate change is a very complex and challenging problem, and it is still necessary to carry out more in-depth research since there are still some uncertainties in the results of this study. For example, more efforts should be made to more comprehensively investigate the contribution of urbanization to the change in the annual temperature and precipitation, extreme climate, latent heat flux at the land surface, wave flux at ground surface, and so forth. Meanwhile, it is necessary to carry out further research on how to quantitatively measure the inner link between the urban development and climate factors and how this inner link will change as the climate factors change. For instance, this study demonstrates that the urban expansion was the most significant land use and land cover change in the study area during 1995-2005, which influenced the regional temperature and precipitation to some degree. There was an obvious warming effect in the urbanized regions and their surrounding regions, where the precipitation amount also increased to some degree. The urban area in this region would increase continuously, and the urban expansion leads to the continual rise of local temperature and will make the precipitation in summer show an increasing trend during 2030-2040. These changes were all due to the complex interactions between the land surface and urban process.

The results of this study indicate that the anthropogenic land cover change has significant impacts on the regional climate of the Beijing-Tianjin-Tangshan Metropolitan area, which can provide scientific reference for the optimization of the future land use in consideration of the regional climate change. The government can take some useful measures according to the result of this study to mitigate the climate change. For example, it is necessary for the government to increase the proportion of the urban green land in the urban land use planning and Consider the urban forests as an important component of the ecological infrastructure to promote the ability of cities to adapt to climate change since the urbanization will continue. Besides, it is urgent to regulate the balance between supply and demand of water resources and reinforce the ability of cities to cope with the flood damage since the future climate change may decrease the stability of the water supply system and consequently threaten the water supply safety in the water sources of the Beijing-TianjinTangshan Metropolitan area. For example, the government should adjust the design standards of infrastructures such as the water reservoirs, flood control facilities, and drainage systems and integrate the water drainage function of the rainwater collection system and natural landscapes in order to improve the ability of cities to cope with rainstorms. In addition, it is necessary to implement the retreat plans in the regions susceptible to floods or set these regions as parks so as to reduce the loss from floods to the smallest extent. Meanwhile, it is urgent to improve the ability to monitor, forecast, and cope with the extreme weather events.

\section{Conflict of Interests}

The authors declare that there is no conflict of interests regarding the publication of this paper.

\section{Acknowledgments}

This research was supported by the National Program for Developing Basic Science in China (Grant no. 2010CB950900). Data support from the projects funded by the National Natural Science Foundation of China is also appreciated (Grant no. 41171434, Grant no. 70503025, and Grant no. 70873118). 


\section{References}

[1] World Resources Institute, World Resources 1996-97: The Urban Environment, World Resources Institute, 1996.

[2] UN, World Urbanization Prospects: The 2003 Revision, United National Population Division, Department of Economic and Social Affairs, United Nations Secretariat, New York, NY, USA, 2004.

[3] Chinese Academy of Social Sciences, Blue Book on Micro Economy, Chinese Academy of Social Sciences, 2010.

[4] R. A. Pielke Sr., G. Marland, R. A. Betts et al., "The influence of land-use change and landscape dynamics on the climate system: relevance to climate-change policy beyond the radiative effect of greenhouse gases," Philosophical Transactions of the Royal Society A, vol. 360, no. 1797, pp. 1705-1719, 2002.

[5] D. J. Sailor, "Simulated urban climate response to modifications in surface albedo and vegetative cover," Journal of Applied Meteorology, vol. 34, no. 7, pp. 1694-1704, 1995.

[6] Q. Weng, "Fractal analysis of satellite-detected urban heat island effect," Photogrammetric Engineering \& Remote Sensing, vol. 69, no. 5, pp. 555-566, 2003.

[7] T. R. Oke, "The energetic basis of the urban heat island," Quarterly Journal, Royal Meteorological Society, vol.108, no. 455, pp. 1-24, 1982.

[8] D. A. Quattrochi, J. C. Luvall, D. L. Rickman, J. Estes M.G., C. A. Laymon, and B. F. Howell, "A decision support information system for urban landscape management using thermal infrared data: decision support systems," Photogrammetric Engineering \& Remote Sensing, vol. 66, no. 10, pp. 1195-1207, 2000.

[9] Z. Bottyán, A. Kircsi, S. Szegedi, and J. Unger, "The relationship between built-up areas and the spatial development of the mean maximum urban heat island in Debrecen, Hungary," International Journal of Climatology, vol. 25, no. 3, pp. 405-418, 2005.

[10] M. S. Alonso, J. L. Labajo, and M. R. Fidalgo, "Characteristics of the urban heat island in the city of Salamanca, Spain," Atmósfera, vol. 16, no. 3, pp. 137-148, 2003.

[11] J. Unger, Z. Sümeghy, and J. Zoboki, “Temperature cross-section features in an urban area," Atmospheric Research, vol. 58, no. 2, pp. 117-127, 2001.

[12] K. Klysik and K. Fortuniak, "Temporal and spatial characteristics of the urban heat island of Lodz, Poland," Atmospheric Environment, vol. 33, no. 24-25, pp. 3885-3895, 1999.

[13] R. D. Bornstein, "Observations of the urban heat island effect in New York city," Journal of Applied Meteorology, vol. 7, no. 4, pp. 575-582, 1968.

[14] E. Kalnay and M. Cai, "Impact of urbanization and land-use change on climate," Nature, vol. 423, no. 6939, pp. 528-531, 2003.

[15] E. Sertel, C. Ormeci, and A. Robock, "Modelling land cover change impact on the summer climate of the Marmara Region, Turkey," International Journal of Global Warming, vol. 3, no. 1, pp. 194-202, 2011.

[16] Y. Lin, A. Liu, E. Ma, X. Li, and Q. Shi, "Impacts of future urban expansion on regional climate in the Northeast Megalopolis, USA," Advances in Meteorology, vol. 2013, Article ID 362925, 10 pages, 2013.

[17] M. Georgesce, M. Moustaoui, A. Mahalov, and J. Dudhia, "Summertime climate impacts of projected megapolitan expasion in Arizona," Natural Climate Change, vol. 3, no. 1, pp. 37-41, 2012.

[18] S. A. Changnon Jr. and F. A. Huff, "The urban-related nocturnal rainfall anomaly at St. Louis," Journal of Climate \& Applied Meteorology, vol. 25, no. 12, pp. 1985-1995, 1986.
[19] F. A. Huff and J. L. Vogel, "Urban, topographic and diurnal effects on rainfall in the St. Louis region," Journal of Applied Meteorology and Climatology, vol. 17, no. 5, pp. 565-577, 1978.

[20] J. L. Vogel and F. A. Huff, "Relation between the St. Louis Urban rainfall anomaly and synoptic weather factors," Journal of Applied Meteorology and Climatology, vol. 17, no. 17, pp. 1141$1152,1978$.

[21] J. M. Shepherd, H. Pierce, and A. J. Negri, "Rainfall modification by major urban areas: observations from spaceborne rain radar on the TRMM satellite," Journal of Applied Meteorology, vol. 41, no. 7, pp. 689-701, 2002.

[22] M. R. Hjelmfelt, "Numerical simulation of the effects of St. Louis on mesoscale boundary-layer airflow and vertical air motion: simulations of urban vs non-urban effects," Journal of Applied Meteorology, vol. 21, no. 9, pp. 1239-1257, 1982.

[23] K. J. Craig and R. D. Bornstein, "MM5 simulation of urban induced convective precipitation over Atlanta," in Proceedings of the 4th Symposium on the Urban Environment, San Jose Sate University, Norfolk, Va, USA, 2002.

[24] C. M. Rozoff, W. R. Cotton, and J. O. Adegoke, "Simulation of St. Louis, Missouri, land use impacts on thunder storms," Journal of Applied Meteorology, vol. 42, no. 6, pp. 716-738, 2003.

[25] V. D. Heever, C. Susan, and W. R. Cotton, "Urban aerosol impacts on downwind convective storms," Journal of Applied Meteorology and Climatology, vol. 46, no. 6, pp. 828-850, 2007.

[26] H. L. Thompson, Modelling the impact of urbanisation on the regional climate of the Greater London area [Ph.D. thesis], University of Birminghan, 2009.

[27] X. Deng, J. Huang, S. Rozelle, and E. Uchida, "Growth, population and industrialization, and urban land expansion of China," Journal of Urban Economics, vol. 63, no. 1, pp. 96-115, 2008.

[28] X. Deng, J. Huang, S. Rozelle, and E. Uchida, "Economic growth and the expansion of urban land in China," Urban Studies, vol. 47, no. 4, pp. 813-843, 2010.

[29] L. Jiang, X. Deng, and S. Karen, "Multi-level modeling of urban expansion and cultivated land conversion for urban hotspot counties in China," Landscape and Urban Planning, vol. 108, no. 2-4, pp. 131-139, 2012.

[30] T. Tang, S. Ran, and M. Tan, "Urbanization and its impact on the evapotranspiration in Beijing-Tianjin-Tangshan area," Journal of Geo-Information Science, vol. 15, no. 2, pp. 233-240, 2013.

[31] C. L. Zhang, F. Chen, S. G. Miao, Q. C. Li, X. A. Xia, and C. Y. Xuan, "Impacts of urban expansion and future green planting on summer precipitation in the Beijing metropolitan area," Journal of Geophysical Research D, vol. 114, no. 2, Article ID D02116, 2009.

[32] J. Liu and X. Deng, "Influence of different land use on urban microenvironment in Beijing City, China," Journal of Food, Agriculture and Environment, vol. 9, no. 3-4, pp. 1005-1011, 2011.

[33] X. Deng, C. Zhao, and H. Yan, "Systematic modeling of impacts of land use and land cover changes on regional climate: a review," Advances in Meteorology, vol. 2013, Article ID 317678, 11 pages, 2013.

[34] W. Kuang, J. Liu, and Q. Shao, "Simulating dynamic urban expansion at reginal scale in Beijing-Tianjin-Tangshan metropolitan area," Journal of Geographic Science, vol. 66, no. 2, pp. 178$188,2011$.

[35] M. Mohan and S. Bhati, "Analysis of WRF model performance over subtropical region of Delhi, India," Advances in Meteorology, vol. 2011, Article ID 621235, 13 pages, 2011. 
[36] J. Chen, P. Zhao, H. Liu, and X. Guo, "Modeling impacts of vegetation in western China on the summer climate of northwestern China," Advances in Atmospheric Sciences, vol. 26, no. 4, pp. 803$812,2009$.

[37] A. Garcia, T. Schoenemeyer, A. Jazcilevich, G. Ruiz-Suarez, and V. Fuentes-Gea, "Implementation of the multiscale climate chemistry model (MCCM) for Central Mexico," in Proceedings of the 8th International Conference on Air Pollution, vol. 8, pp. 71-78, July 2000.

[38] A. D. Jazcilevich, A. R. García, and L. G. Ruíz-Suárez, "A modeling study of air pollution modulation through land-use change in the Valley of Mexico," Atmospheric Environment, vol. 36, no. 14, pp. 2297-2307, 2002.

[39] M. Wang, X. Yan, J. Liu, and X. Zhang, "The contribution of urbanization to recent extreme heat events and a potential mitigation strategy in the Beijing-Tianjin-Heibe metrololitan area," Theoretical and Applied Climatology, 2013.

[40] R. Qu, X. Cui, H. Yan, E. Ma, and J. Zhan, "Impacts of land cover change on the near-surface temperature in the North China Plain," Advances in Meteorology, vol. 2013, Article ID 409302, 12 pages, 2013.

[41] K. E. Taylor, R. J. Stouffer, and G. A. Meehl, "An overview of CMIP5 and the experiment design," Bulletin of the American Meteorological Society, vol. 93, no. 4, pp. 485-498, 2012.

[42] J. Liu, M. Liu, D. Zhuang, Z. Zhang, and X. Deng, "Study on spatial pattern of land-use change in China during 1995-2000," Science in China D, vol. 46, no. 4, pp. 373-384, 2003.

[43] J. Liu, Z. Zhang, X. Xu et al., "Spatial patterns and driving forces of land use change in China during the early 21st century," Journal of Geographical Sciences, vol. 20, no. 4, pp. 483-494, 2010.

[44] J. Wang, C. He, Y. Dong, L. Gao, and W. Xu, "Analysis of land use cover driving forces in the urban fringe of Beijing city," Andvance in Sciences, vol. 17, pp. 201-208, 2002.

[45] L. Bounoua, A. Safia, J. Masek, C. Peters-Lidard, and M. L. Imhoff, "Impact of urban growth on surface climate: a case study in Oran, Algeria," Journal of Applied Meteorology and Climatology, vol. 48, no. 2, pp. 217-231, 2009.

[46] Y. Ezber, O. L. Sen, T. Kindap, and M. Karaca, "Climatic effects of urbanization in Istanbul: a statistical and modeling analysis," International Journal of Climatology, vol. 27, no. 5, pp. 667-679, 2007.

[47] J. A. Voogt and C. S. B. Grimmond, "Modeling surface sensible heat flux using surface radiative temperatures in a simple urban area," Journal of Applied Meteorology, vol. 39, no. 10, pp. 16791699, 2000.

[48] F. Miglietta, B. Gioli, Y. Brunet et al., "Sensible and latent heat flux from radiometric surface temperatures at the regional scale: methodology and evaluation," Biogeosciences, vol. 6, no. 10, pp. 1975-1986, 2009.

[49] S.-G. Miao, F. Chen, Q.-C. Li, and S.-Y. Fan, "Month-averaged impacts of urbanization on atmospheric boundary layer structure and precipitation in summer in Beijing area," Chinese Journal of Geophysics, vol. 53, no. 7, pp. 1580-1593, 2010.

[50] J. Marshall Shepherd, M. Carter, M. Manyin, D. Messen, and S. Burian, "The impact of urbanization on current and future coastal precipitation: a case study for Houston," Environment and Planning B, vol. 37, no. 2, pp. 284-304, 2010.

[51] J. M. Shepherd and T. L. Mote, "Urban effects on rainfall variability: potential implications for Georgia's water supply," in Proceedings of the Georgia Water Resources Conference, Athens, Ga, USA, 2009. 

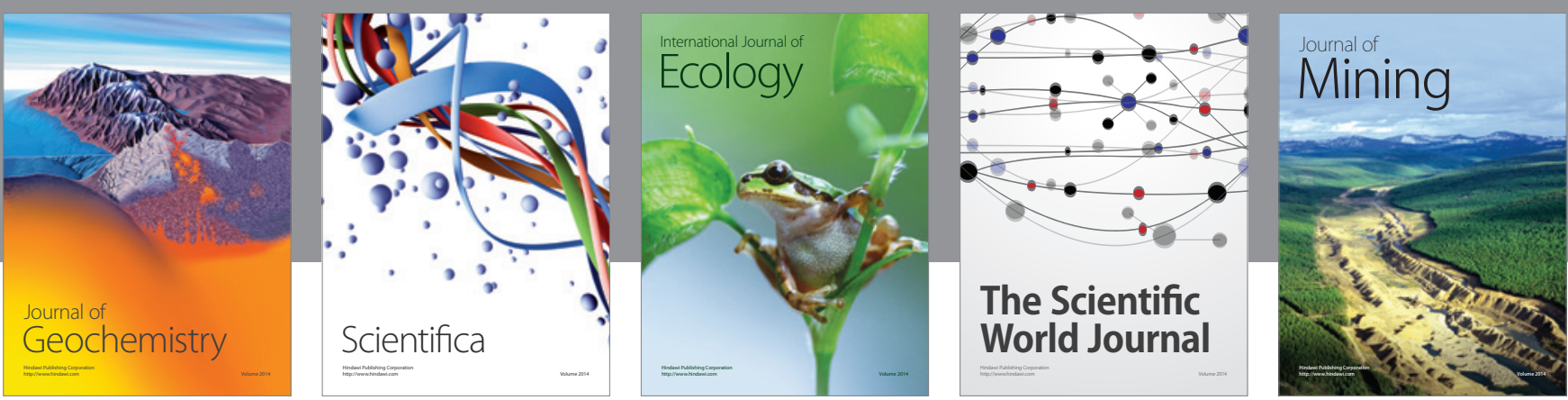

The Scientific World Journal
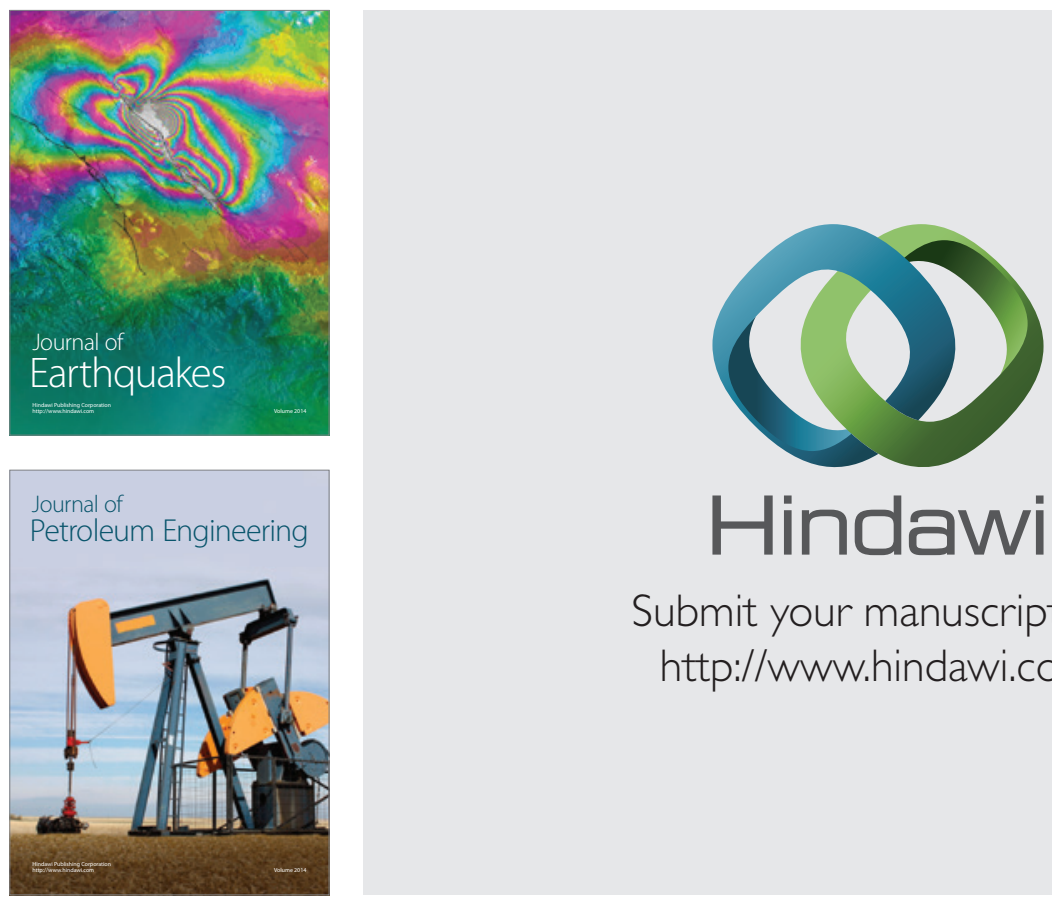

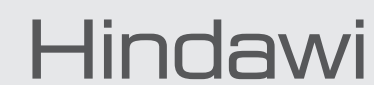

Submit your manuscripts at

http://www.hindawi.com
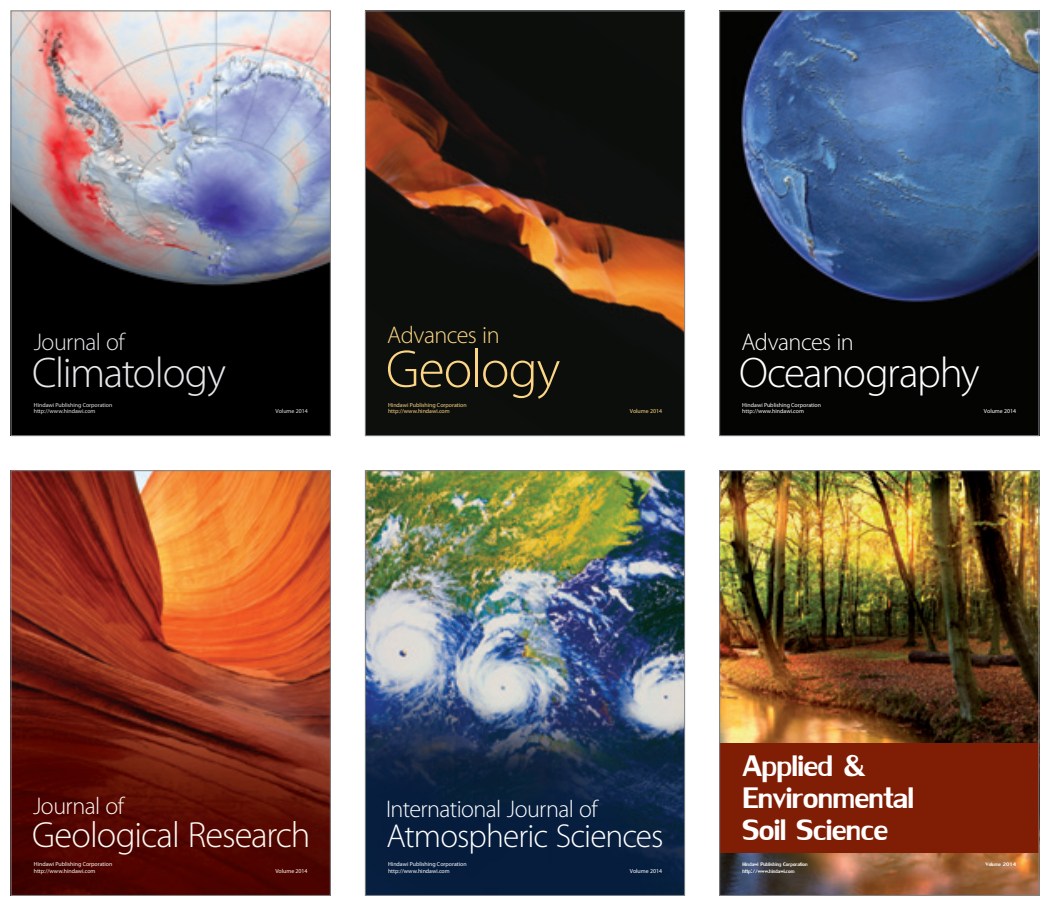
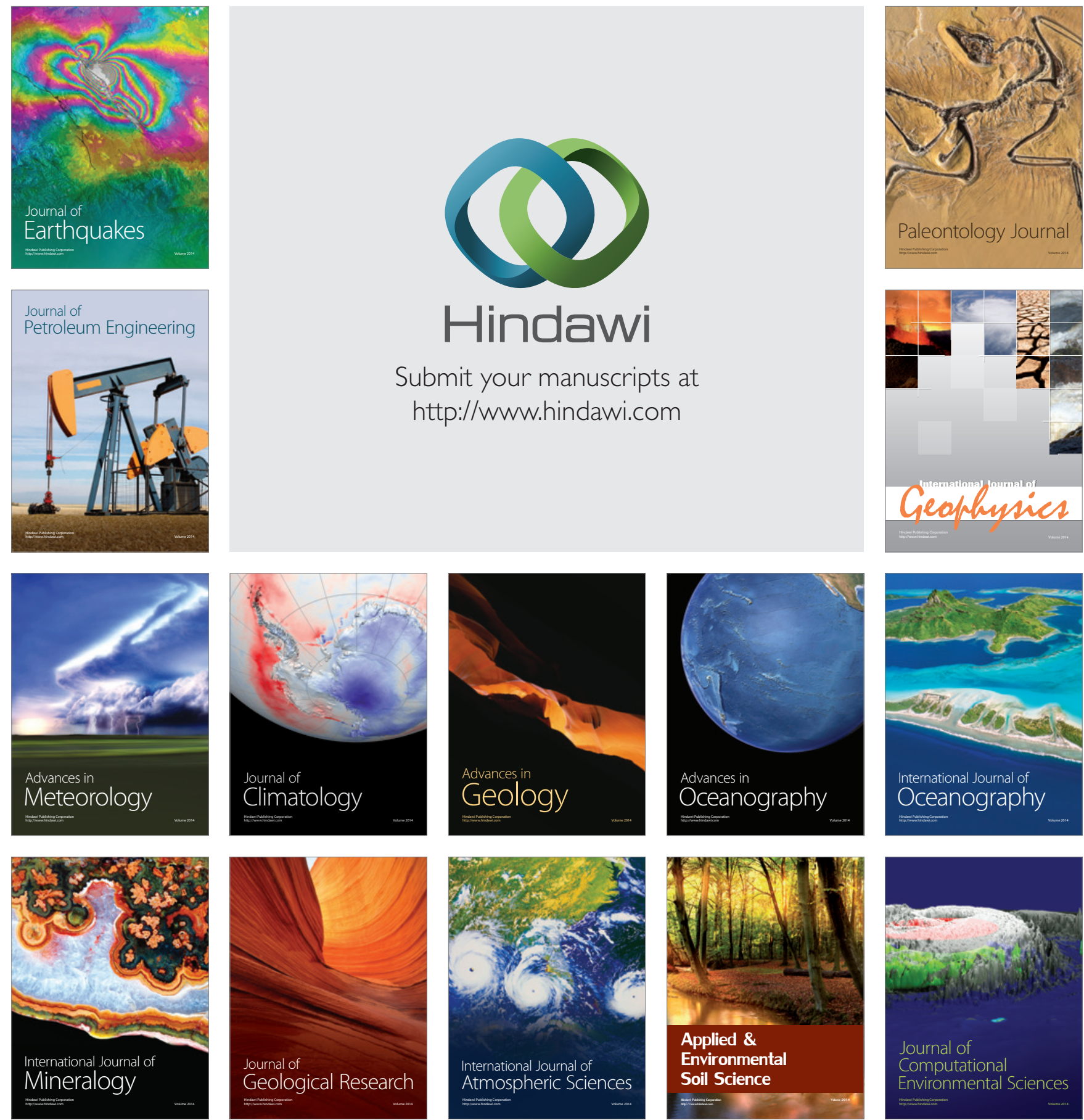